\title{
Ultrastructural studies on the host-parasite interface between Khawia sinensis (Cestoda: Caryophyllidea) and carp Cyprinus carpio
}

\author{
N. J. Morley, D. Hoole* \\ Parasitology Research Group, Centre for Applied Entomology and Parasitology, Department of Biological Sciences, \\ Keele University, Keele, Stafiordshire ST5 5BG, United Kingdom
}

\begin{abstract}
Ultrastructural studies were undertaken of the host-parasite interface between Khawia sinensis Hsü, 1935 and Cyprinus carpio L. Pathology induced in the gut included loss of microvilli, compression of enterocytes and shedding of host material into the gut lumen. An interface layer occurred between the gut wall and the neck and posterior scolex of the parasite. A cellular response, which was evoked either by the worm or the damage induced, comprised eosinophils, macrophages and lymphocytes. Such leucocytes were also found in close association with the worm tegument.
\end{abstract}

KEY WORDS: Khawia sinensis - Cyprinus carpio - Pathology - Ultrastructure - Leucocytes

\section{INTRODUCTION}

Khawia sinensis, a pathogenic, intestinal, monozoic tapeworm which causes the disease khawiosis in carp Cyprinus carpio L., originated in China. Over recent years the disease has spread throughout Asia and Europe and was first recorded in the UK by Chubb \& Yeomans in 1993. The life cycle has recently been experimentally confirmed as utilising a number of species of tubificid worms as intermediate hosts (Scholtz et al. 1990, Scholtz 1991a, b), predominantly Tubifex tubifex and Limnodrilus udekemiamus, and the adult worm which occurs in the fish definitive host has been recorded as being up to $170 \mathrm{~mm}$ in length (Musselius et al. 1963). Most studies to date have concentrated on parasite development (e.g. Kulakovskaya 1962, Sapozhnikov 1972, Demshin \& Dvaryadkin 1980), blood and metabolic changes induced by the worm in the fish (Sapozhnikov 1973, Lozinska-Gabska 1981, Niemczuk 1991), and control (e.g. Zelazny \& Panczyk 1984). The limited number of light microscopical studies on the pathology associated with the infection (Musselius et al. 1963, Kapustina 1978, Jara \&

·Addressee for correspondence; E-mail: bia10@keele.ac.uk
Szerow 1981) have revealed that the gross effects of khawiosis include irritation, inflammation and perforation of the gut mucosa with fatalities usually occurring with 35 to 45 worms per fish. It is somewhat surprising given the ubiquitous nature of intestinal metazoans and the numerous descriptions using light microscopy of intestinal cestodes that detailed ultrastructural investigations have been carried out on only a few species, e.g. Caryophyllaeus laticeps by Karanis \& Taraschewski (1993), Bothriocephalus acheilognathi by Hoole \& Nisan (1994).

The present study was undertaken to elucidate the ultrastructural details of the intestinal pathological response of carp to Khawia sinensis and to establish the involvement, if any, of the leucocyte component within the response. The investigation forms the basis of more extensive studies on the immune response of cultured carp to this pathogenic tapeworm.

\section{MATERIALS AND METHODS}

Pieces of intestine with tapeworms (length 5 to $70 \mathrm{~mm}$ ) attached were removed in $0.85 \%$ saline from naturally infected, freshly killed carp (Cyprinus carpio L.; wet weight 1 to $600 \mathrm{~g}$ ) obtained from the National Rivers 


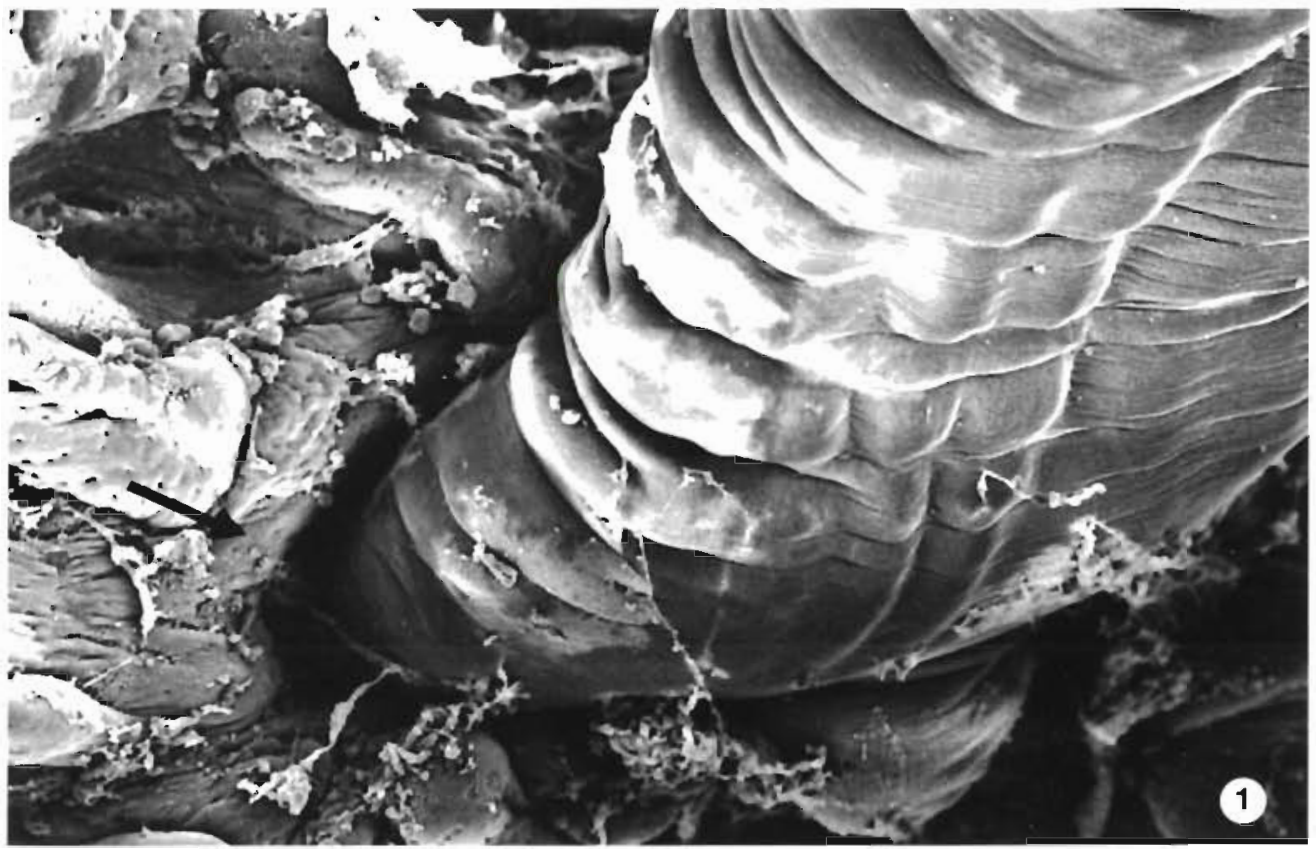

Fig. 1. Scanning electron micrograph of Khawia sinensis in the intestine of Cyprinus carpio. Note flattening of the gut epithelium adjacent to the worm (arrow) $(\times 300)$

Authority (Anglian and Thames Divisions). Material was fixed in $4 \%$ glutaraldehyde in $0.1 \mathrm{M}$ phosphate buffer, $\mathrm{pH} 7.2$, for $18 \mathrm{~h}$, washed for $3 \mathrm{~h}$ in $0.1 \mathrm{M}$ phosphate buffer and post-fixed in $1 \%$ aqueous osmium tetroxide for $1 \mathrm{~h}$. After washing in 2 changes of distilled water, dehydration was carried out in a graded series of ethanols before embedding in Spurr's resin. Sections were stained in uranyl acetate and lead citrate and observed on a Jeol $100 \mathrm{CX}$ Il electron microscope at $80 \mathrm{KV}$.

For scanning electron microscopy, the fixed material was dehydrated in a graded series of acetone, transferred to liquid $\mathrm{CO}_{2}$ and critical-point dried. The dried specimens were mounted on metal stubs, sputtered with gold and examined with a Jeol $100 \mathrm{~T}$ scanning electron microscope.

As a control corresponding regions of the intestine from fish not infected with Khawia sinensis were processed for electron microscopy and examined for leucocyte infiltration and the normal appearance of enterocytes.

\section{RESULTS}

Worms were found anteriorally within the intestines, where they occurred either singularly or more commonly in clusters of up to 6 . The parasite comprised a cuneifimbriate scolex which lacked any specialized attachment organs, and to maintain its position in the gut it would appear that the worm formed an intimate contact with the gut mucosa which extended around both the scolex and neck region (Fig. 1). Despite this form of adhesion there was minimal damage to the surrounding gut wall which had a slight flattening of the epithelium adjacent to the parasite (Fig. 1 arrow) and an increase in mucus occurring over both the gut wall and worm.

Transmission electron microscopical observations however revealed that damage to the gut epithelium occurred in all infected fish. This damage appeared to be limited to areas where the worm was in intimate contact with the gut wall and was most extensive therefore at the anterior scolex and decreased in intensity posteriorally towards the neck of the parasite and appeared to be the same in each individual despite differences in the sizes of parasites. At the posterior scolex and neck region of the attachment loss of microvilli from the apical surface of the enterocytes occurred (Fig. 2a). Further anteriorally, however, the scolex, which was more deeply buried, appeared to induce compression of the gut mucosa. Adjacent to the posterior region of the scolex this compaction was restricted to individual cells (Fig. 2b); however, more anteriorally this was found to encompass larger areas

Fig. 2. Transmission electron micrographs of Khawia sinensis in the intestine of Cyprinus carpio. (a) Worm (W) in intimate contact with gut wall $(\mathrm{g})$. Note the absence of microvilli on the surface of enterocyte $(e)(\times 11.600)$. (b) Compression of an enterocyte $(e)$ in contact with the worm (W) $(\times 9600)$. (c) Compression of tissue adjacent to the scolex (SC) of the parasite $(\times 5800)$ 


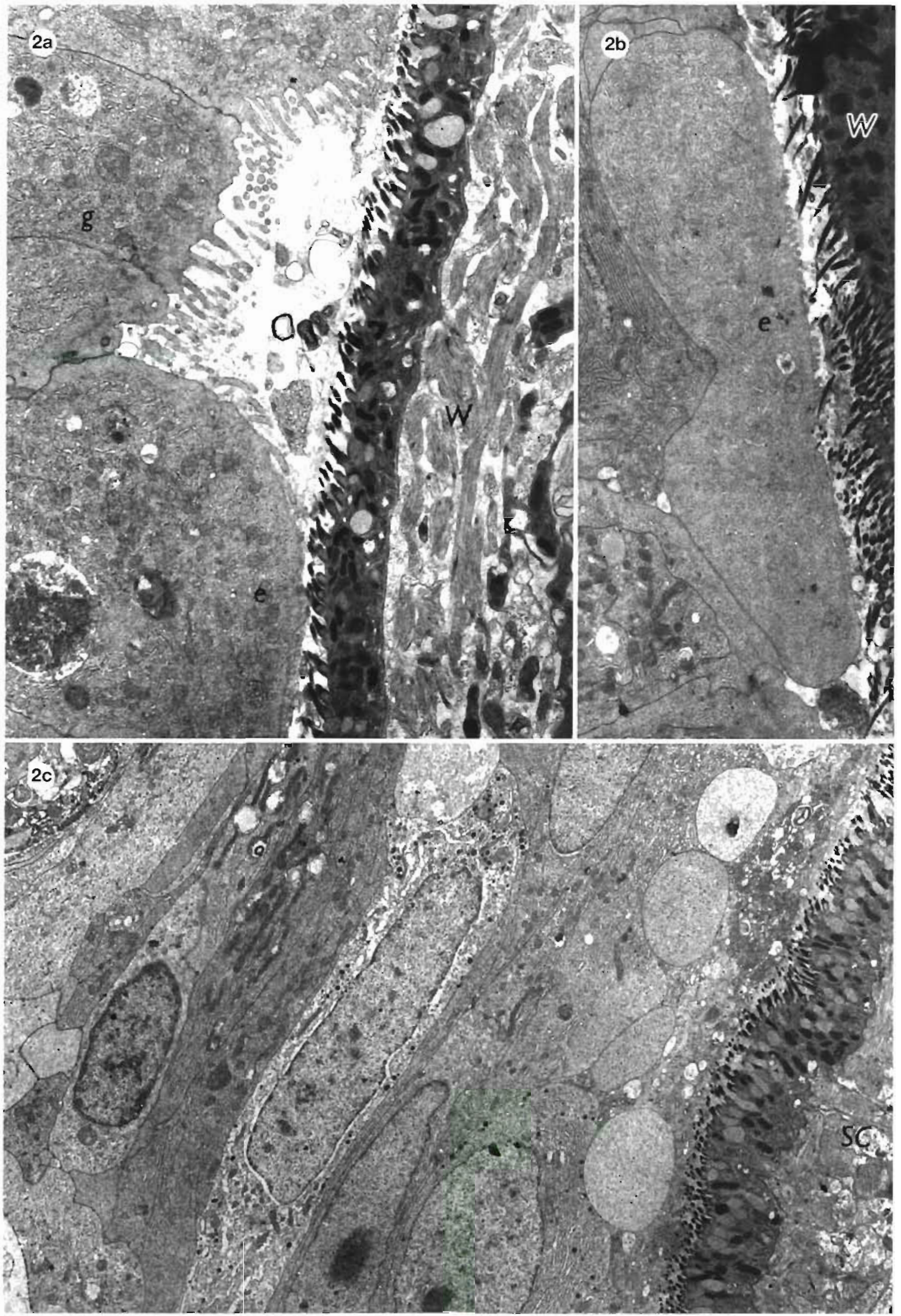



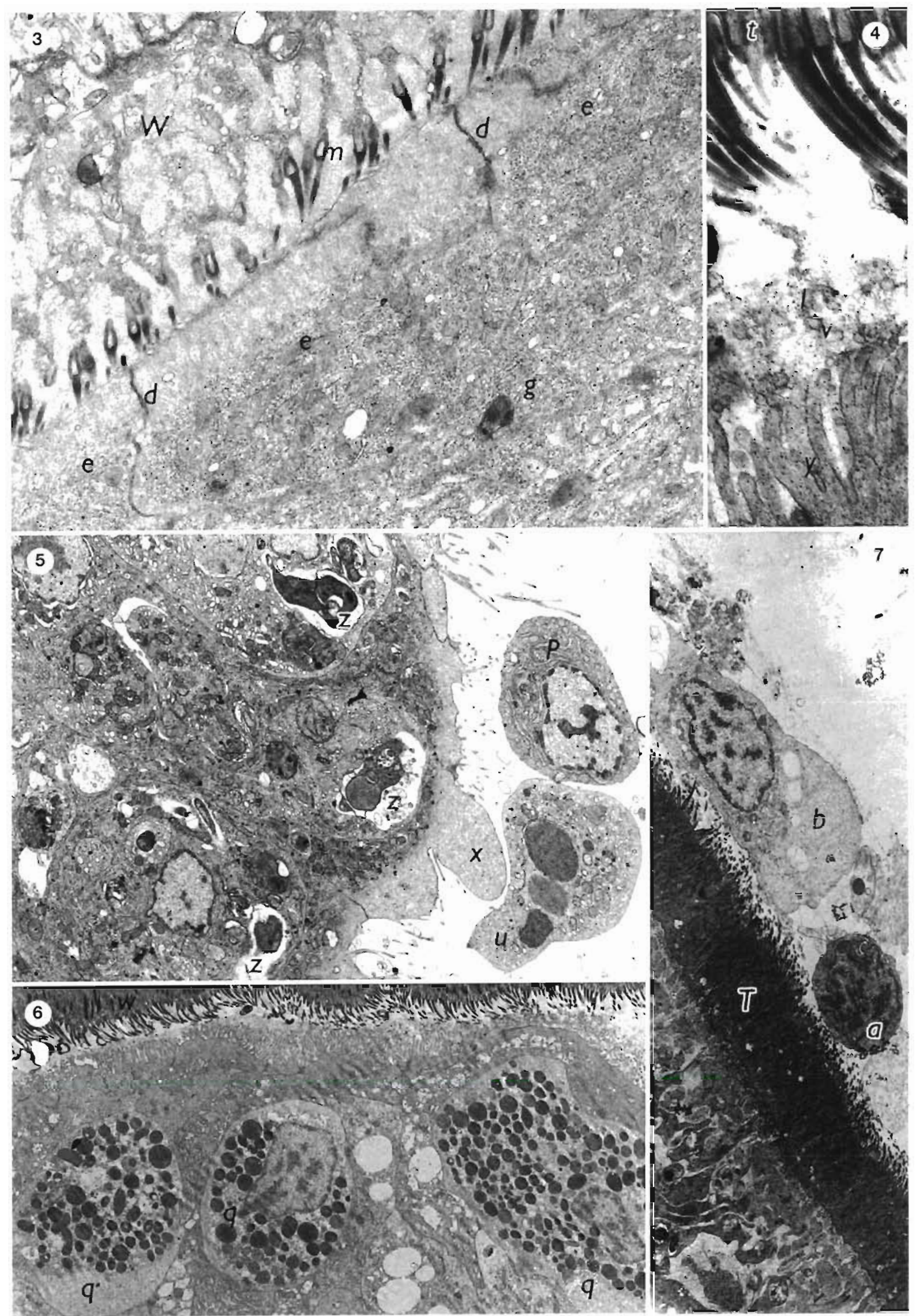
of the surrounding tissue (Fig. 2c). Despite this alteration in the cellular component of the gut, disruption of the desmosome junction between adjacent enterocytes did not occur (Fig. 3). Where worm and host were not in direct contact they were separated by an intermediate layer which comprised an amorphous material with occasional membrane-bound vesicles (Fig. 4).

In fish which contained older infections, as judged by the length of the individual parasite, enterocytes which contained extensive vacuolation and comprised large cytoplasmic projections containing few organelles (Fig. 5). These vacuoles, which were 3 by $2 \mu \mathrm{m}$ and contained electron-dense material and membrane fragments, were also associated with damaged epithelium which was being shed into the gut lumen. Such vacuoles may thus be indicative of autolysis.

The parasite evoked a cellular response within the gut wall. This appeared to be much more intensive with the larger worms (>20 mm) than with the smaller individuals (<20 mm). Intact lymphocytes, macrophages and eosinophils were found either singularly or accumulated in small groups close to the laminal surface (Fig. 6). In addition, intact leucocytes also occurred in the gut lumen sometimes attached to the tegument of the worm (Fig. 7). Although there is an association between the parasite and the cellular components of the immune response, there was no evidence of damage to the worm. Immune cells within the lumen, however, did appear active as some macrophages contained phagocytosed bacteria.

\section{DISCUSSION}

There have been several light microscopical studies on gross pathological effects induced in the gut of carp by infections with Khawia sinensis. Jara \& Szerow (1981) noted that the parasite caused enteritis, often associated with congestion and oedema of the intestinal wall, and also intensive myxiosis. In addition, as a result of pressure from the scolex the intestinal epithelium was damaged or atrophied. The typical enteritis symptoms found were accompanied by the appearance of rodlet cells (Stäbchendrüsenzellen) in the epithelium and by irritation of connective tissue in the mucosa and submucosa. In our ultrastructural study, however, such cells were not observed. This absence may possibly mean that these cells do not accumulate adjacent to the parasite or alternatively that they are only found in heavy infections. That the effect of khawiosis is dependant on parasite burden is illustrated by the work of Musselius et al. (1963), who found irritation, inflammation and perforation of the gut mucosa with fatalities occurring at 35 to 45 worms per fish and Kapustina (1978), who discovered that there was no significant effect below 10 parasites per fish.

Based on observations made on carp infected with Khawia iowensis, Mackiewicz et al. (1972) attributed much of the tissue alterations in the gut to the lack of specific attachment organs such as loculi, acetabula or bothria, a common feature of many members of the Caryophyllidean family. In contrast, $K$. sinensis induces inflammation or ulceration and, as our ultrastructural studies have revealed, microvilli and enterocyte loss, autolysis and leucocyte infiltration. In addition, although autolysis occurs as a normal process in enterocyte turnover, that observed in infected fish was particularly associated with worm attachment sites. The differential response induced by these 2 species of Khawia may also be affected by other parameters. For example $K$. iowensis is evenly distributed throughout the gut (Calentine \& Ulmer 1961) whilst, as Musselius et al. (1963) revealed and we.confirmed in the present study, $K$. sinensis may be found grouped together in clusters. The adults of $K$. iowensis are also significantly smaller (11 to $26 \mathrm{~mm}$; Calentine \& Ulmer 1961) than those of $K$. sinensis (50 to $170 \mathrm{~mm}$; Musselius et al. 1963) and thus perhaps induce less irritation to the gut.

Kapustina (1978) noted that, although lesions were not observed at the site of attachment, the area of intestinal mucosa adjacent to the strobila of Khawia sinensis was damaged. This was attributed to the 'type of nutrition of the cestode' although the possibility that the parasite migrates in the gut cannot be excluded and that such damage may in fact be old sites of attachment rather than irritation by the strobila. In contrast. our ultrastructural observations have confirmed the light microscope studies of Jara \& Szerow (1981), who revealed that damage to the gut occurred mainly at the attachment site.

Figs. 3 to 7. Transmission electron micrographs of Khawia sinensis in the intestine of Cyprinus carpio. Fig. 3. Intimate contact between worm (W) and the gut wall (g). Note that, although microtriches (m) of the parasite are adjacent to enterocytes (e) which are denuded of microvilli, disruption of the desmosome junction (d) between the cells does not occur $(\times 12960)$. Fig. 4 . Amorphous intermediate layer (l) containing vesicles (v) occurs between parasite tegument (t) and microvilli (y) of the gut ( $\times 25200)$. Fig. 5 . Areas of the gut with large cytoplasmic projections $(x)$ which contain vacuoles (v), but lack organelles. Note the plasma cell (p) and a cell of unknown origin $(u)$ in the lumen $(\times 4860)$. Fig. 6 . Accumulation of eosinophils $(q)$ within the gut wall adjacent to the parasites neck region $(w)(\times 3915)$. Fig. ?. Intact leucocytes, lymphocytes (a) and macrophages (b), attached to the tegument (T) of the worm within the gut lumen $(\times 3915)$ 
Despite the wide differences in the sizes of the worms found (lengths ranged from 5 to $70 \mathrm{~mm}$ ), and presumably age of infections, the damage observed to the gut wall at the ultrastructural level was the same. The ultrastructural damage is comparable with the findings of Karanis and Taraschewski (1993) in their electron microscope investigations of Caryophyllaeus laticeps, another caryophyllidean worm with an unspecialized scolex. As a consequence of lacking specialized attachment organs, Caryophyllaeus laticeps appears to initiate a very intimate host-parasite interface which results in the epithelial cells becoming heavily compressed and may result in their eventual degeneration. However, recent ultrastructural studies by Hoole and Nisan (1994) on carp infected with Bothriocephalus acheilognathi have revealed that damage was restricted to loss of microvilli and the separation and shedding of enterocytes at the site of attachment. In contrast, our studies have revealed that although shedding of damaged epithelium occurred no separation of enterocytes was found, even where tissue was heavily compressed.

The presence of an amorphous layer between Khawia sinensis and the gut wall of carp is of particular interest. Hayunga (1979a), examining the pathology of a number of caryophyllaeid species in the white sucker, discovered that Hunterella nodulosa, a parasite which also lacks any specialized attachment organs, lives within fibrous nodules just behind the anterior intestinal swelling. This worm does not come into contact with the host tissue but is kept separate by a thin layer of material known as an 'eosinophilic matrix' (Mackiewicz \& McCrae 1962). Histochemical tests suggested that the matrix may be composed of mucoprotein and could have an adhesive, nutritional (Mackiewicz et al. 1972), and/or excretory/secretory role (Hayunga 1979b). Karanis \& Taraschewski (1993) also noted this interface layer between Caryophyllaeus laticeps and the gut of carp and further suggested that the host may also contribute to its formation. In our studies a similar layer was only present in regions where parasite surface was not in contact with the host, i.e. neck and posterior region of the scolex. It was not possible to ascertain the source and role of this layer.

In the present study a distinct cellular response to the parasite, or the damage induced, was evident which was more pronounced with larger worms. This manifests itself in the accumulation of eosinophils and macrophages both within the gut wall and lumen in regions where the worm was found in close association to the epithelium. This infiltration of leucocytes which is a normal non-specific reaction of fish against a parasite (Rowley et al. 1988) was also found by Karanis \& Taraschewski (1993) associated with Caryophyllaeus laticeps infections of cyprinid fish. The presence of lymphocytes within the cellular response may also suggest a specific reaction occurs. Despite this response the parasite appears to be undamaged and further studies are needed to assess the role of each leucocyte within the cellular response and the possible involvement of humoral components.

Acknowledgements. The authors thank Mr Ian Wright for technical assistance and the NRA (Anglian and Thames Divisions) for supplying infected fish.

\section{LITERATURE CITED}

Calentine RL, Ulmer MJ (1961) Khawia iowensis n. sp. (Cestoda: Caryophyllaeidae) from Cyprinus carpio L in Iowa. J Parasitol 47(5):795-805

Chubb JC, Yeomans WE (1993) Khawia sinensis Hsü, 1935 (Cestoda: Caryophyllidea), a tapeworm new to the British Isles. Proc Br Soc Parasitol 29

Demshin NI, Dvoryadkin VA (1980) The biology of Khawia sinensis Hsü, 1935 (Caryophyllidea, Cestoda) - a parasite of the Amur carp. Gidrobiol Zh 16(2):77-82 (in Russian)

Hayunga EG (1979a) Observations on the intestinal pathology caused by three caryophyllidean tapeworms of the white sucker Catostomus commersoni Lacepede. J Fish Dis 2(3): $239-248$

Hayunga EG (1979b) The structure and function of the scolex glands of three caryophyllid tapeworms. Proc helminth Soc Wash 46(2):171-179

Hoole D, Nisan H (1994) Ultrastructural studies on the intestinal response of carp to the pseudophyllidean tapeworm. Bothriocephalus acheilognathi. J Fish Dis 17:623-629

Jara Z, Szerow D (1981) Histopathological changes and localization of the cestode Khawia sinensis in the intestine of carp (Cyprinus carpio). Wiad Parazytol 27(6):695-703 (in Polish)

Kapustina NI (1978) Host-parasite relationships in the system Khawia sinensis - carp in low intensity infections. Tr vses nauchno-issled Inst Prud ryb Khoz (Parazity, bolezni ryb i ikh parazity) 27:75-87 (in Russian)

Karanis P, Taraschewski H (1993) Host-parasite interface of Caryophyllaeus laticeps (Eucestoda: Caryophyllidae) in three species of fish. J Fish Dis 16:371-379

Kulakovskaya OP (1962) The development of Caryophyllaeidae (Cestoda) in the intermediate host. Zool Zh 41(7): 986-992 (in Russian)

Lozinska-Gabska M (1981) Aspartate and alanine aminotransferase activity in the intestine of carp (Cyprinus carpio) infected with the cestodes Bothriocephalus gowkongensis or Khawia sinensis. Wiad Parazytol 27(6):717-743 (in Polish)

Mackiewicz JS, Cosgrove EG, Grude DW (1972) Relationship of pathology to scolex morphology among Caryophyllid cestodes. Z Parasitenkd 39:233-246

Mackiewicz JS, McCrae R (1962) Hunterella nodullosa gen.n., sp.n. (Cestoidea: Caryophyllaeidae) from Catostomus commersoni (Lacepede) (Pisces: Catostomidae) in North America. J Parasitol 48(6):798-806

Musselius V, Ivanova N, Laptev V, Apazidi L (1963) Khawia sinensis Hsü, 1935 of carp. Ribovodstvo i Ribolovstvo 1963. No. 3:25-27 (in Russian)

Niemczuk W (1991) Histological and Histochemical-enzymatic changes in the internal organs of carp infected with the 
cestodes Khawia sinensis or Bothriocephalus acheilognathi. Zesz Nauk Akad Rolniczej Wroclawiu, Weterynaria No. 47:21-42 (in Polish)

Rowley AF, Hunt TC, Page M, Mainwaring G (1988) Fish. In: Rowley AF, Ratcliffe NA (eds) Vertebrate blood cells Cambridge University Press, Cambridge, p 19-127

Sapozhnikov GI (1972) The Blology of Khawia in carp. Byull Vses Inst Gel'mintologii KI Skryabina No 7:31-34 (in Russian)

Sapozhnikov Gl (1973) A clinical study of Khawia sinensis infection in carp. In: Gagarin VG (ed) Problemy obshchei i prikladnoi gel'mintologii, p 331-336 (in Russian)

Scholtz T (1991a) Early development of Khawia sinensis Hsü,

Responsible Subject Editor: W. Körting, Hannover, Germany
1935 (Cestoda: Caryophyllidea), a carp parasite. Folia Parasitol 38:133-142

Scholtz T (1991b) Development of Khawia sinensis Hsü, 1935 (Cestoda: Caryophyllidea) in the fish host. Folia Parasitol $38: 225-234$

Scholtz T, Speta V, Zajicek J (1990) L.lfe history of the tapeworm Khawia sinensis Hsü, 1935, a carp parasite, in the pond Drazsky Skalicany near Blatina, Czechoslovakia. Acta Vet (Belgr) 59:51-63

Zelazny J, Panczyk J (1984) Anthelmintic effects of some nicosamide preparations against Khawia sinensis (Hsü, 1935) in carp. Med Weterynaryjna 40(6):365-368 (in Polish)

Manuscript first received: December 8, 1994 Revised version accepted: June 6, 1995 